\title{
OS SENTIMENTOS DAS MULHERES PÓS-MASTECTOMIZADAS
}

\author{
The feelings of women post mastectomized \\ Los sentimientos de la mujer post-mastectomizada
}

Fernanda Maria de Jesus Sousa de Pires Moura ${ }^{1}$

Lara de Jesus Sousa Pires de Moura ${ }^{4}$
Michelly Gomes da Silva²

Suziane Carvalho de Oliveira ${ }^{3}$

\section{RESUMO}

Pesquisa qualitativa, que objetivou: descrever os sentimentos das mulheres sobre o câncer de mama e discutir as mudanças ocorridas na vida da mulher após o câncer de mama. Ocorreu em um ambulatório de ginecologia de um hospital público de Teresina. Foram entrevistadas 13 mulheres mastectomizadas. Na análise das entrevistas, surgiram três categorias: Sentimentos negativos gerados pela percepção física após mastectomia; Sentimentos positivos gerados pelo conforto espiritual; e Sentimentos gerados pela falta de apoio e atenção dos profissionais durante a assistência. A mudança na vida da mulher com câncer é radical, devido principalmente ao diagnóstico e tratamento. As dificuldades são incalculáveis, pois requerem adaptações profundas no modo de pensar e agir, que influencia física e emocionalmente o convívio pessoal e social.

Palavras-chave: Neoplasias de Mama. Emoções. Mastectomia.

\begin{abstract}
Qualitative research, which aimed to: describe the feelings of women about breast cancer and discuss the changes in a woman's life after breast cancer. It occurred in a gynecology outpatient clinic of a public hospital in Teresina. A total of thirteen women mastectomized. In the analysis of the interviews there were 3 categories: negative feelings generated by the perceived physical after mastectomy, positive feelings generated by the spiritual comfort and feelings generated by the lack of support and attention of professionals for assistance. The change in the lives of women with cancer is radical, mainly due to the diagnosis and treatment. The difficulties are incalculable, since it requires profound changes in the way of thinking and acting, which influences the physical and emotional personal and social interaction.
\end{abstract}

Keywords: Breast câncer. Emotions. Mastectomy

\section{Resumen}

La investigación cualitativa, cuyo objetivo es: describir los sentimientos de las mujeres acerca del cáncer del seno y discutir los cambios en la vida de una mujer después de cáncer de mama. Se produjo en una clínica ambulatoria de ginecología de un hospital público en Teresina. Un total de trece mujeres mastectomizadas. En el análisis de las entrevistas fueron 3 categorías: sentimientos negativos generados por la percepción física después de una mastectomía, sentimientos positivos generados por el confort espiritual y los sentimientos generados por la falta de apoyo y atención de los profesionales de asistencia. El cambio en la vida de las mujeres con cáncer es radical, debido principalmente al diagnóstico y tratamiento. Las dificultades son incalculables, ya que requieren cambios profundos en la manera de pensar y de actuar, lo que influye en el desarrollo físico y emocional, personal y la interacción social.

Palabras clave: Cáncer de mama. Emociones. Mastectomía. 


\section{INTRODUCÃO}

A palavra câncer é vista pela sociedade como um processo irreversível cheio de significados, que representa um grave e contínuo problema de saúde pública. Caracteriza-se por um crescimento desordenado (maligno) que se espalha pelos tecidos e órgãos, invadindo por metástase outras partes do corpo, contando com aproximadamente 100 doenças associadas a essa característica.

Dentre esses 100 tipos de manifestações, o câncer de mama é uma das maiores causas de morte entre as neoplasias malignas no sexo feminino e apresenta-se como o segundo mais incidente, o que o coloca como uma das grandes preocupações para as mulheres e para os serviços de saúde pública no país. ${ }^{2}$

A Organização Mundial da Saúde estima que, por ano, ocorram mais de 1.050 .000 casos novos deste tipo em todo 0 mundo. ${ }^{3} 0$ seu aparecimento é relativamente raro antes dos 35 anos de idade, mas acima desta idade sua incidência cresce rapidamente. Apesar das novas tecnologias, ainda acarreta severos danos na vida das mulheres. ${ }^{4}$

Estudos mostram que uma em cada 15 mulheres irá apresentar algum tipo de problema nas mamas durante a vida, não sendo necessariamente carcinoma de mama; $10 \%$ das mulheres apresentam as chamadas lesões benignas da mama. ${ }^{5}$ Atualmente, no Brasil, apenas 3,4\% dos casos são detectados na fase inicial, enquanto $60 \%$ são diagnosticados em casos avançados, quando a doença já se tornou incurável. ${ }^{6}$

Os fatores de risco estão classificados em muito elevados (mãe ou irmã com câncer de mama na pré-menopausa), mediamente elevados (mãe ou irmã com câncer de mama na pós-menopausa e nuliparidade) e pouco elevados (menarca precoce, menopausa tardia, primeira gestação de termo depois de 34 anos, obesidade, sedentarismo, ingestão alcoólica excessiva e terapia de reposição hormonal por mais de 5 anos). ${ }^{1,7}$

Além disso, estudos epidemiológicos indicam que fatores ambientais são responsáveis por pelo menos $80 \%$ da incidência do câncer de mama. Fatores genéticos representam $5 \%$ a $7 \%$, porém, quando se apresenta antes dos 35 anos, esta frequência chega a $25 \%{ }^{6}$

É bom lembrar que a mama não corresponde apenas ao aspecto físico, ela é vista como um símbolo de feminilidade, por isso é motivo de orgulho para a mulher e admiração para os homens, possuindo um significado afetivo e psicológico. Sendo assim, a palavra câncer traz um estigma muito forte para a mulher, pois além de estar associada à morte, pode afetar uma parte tão valorizada do seu corpo. ${ }^{8}$

Outro ponto importante para aumentar a preocupação em relação ao câncer é o fato de não existir ainda um método que previna o seu aparecimento de maneira eficaz. Desta forma, torna-se essencial a informação às mulheres da real necessidade de detectarem o seu aparecimento nas fases iniciais, por meio do autoexame, que proporciona chance de cura bem maior e tem se mostrado bastante eficiente em evitar complicações mais drásticas. ${ }^{5}$

É extremamente importante 0 autoexame, pois o sinal mais comum do câncer da mama é o aparecimento de um nódulo ou caroço palpável na mama ou na axila, sobretudo quando não desaparece durante o ciclo menstrual e não muda de local quando apalpado, acompanhado ou não de dor. ${ }^{9}$ Também podem surgir alterações na pele que recobre a mama, como abaulamentos ou retrações ou um aspecto semelhante à casca de uma laranja, eritema, alteração da aréola, ulceração, sangramento ou desvio do mamilo. ${ }^{10}$

0 tratamento mais comum é a extração da mama comprometida. Em alguns casos, os médicos vêm fazendo apenas a retirada de partes da mama, através de: quadrantectomia (remoção de um quarto da mama) e lumpectomia (remoção apenas do tumor e de pequena região circunvizinha), obtendo assim bons resultados em termos de sobrevida e melhor efeito estético, já que o órgão é conservado. ${ }^{11}$

A radioterapia e a quimioterapia são tratamentos indicados em casos mais avançados. A escolha do método terapêutico apropriado irá depender de vários fatores, tais como: idade, localização e tamanho do tumor, disponibilidade financeira, análise da mamografia e do modo da paciente lidar com a mama afetada. ${ }^{9}$

Além das implicações relacionadas ao tratamento, devem-se considerar também os efeitos deletérios dessa doença (o medo da morte, da rejeição, de ser estigmatizada, da mutilação, da recidiva, dos efeitos da quimioterapia, incerteza quanto ao futuro e outros), que são representaç̃̃es que têm preocupado os profissionais de saúde envolvidos com a qualidade de vida dessas pacientes. ${ }^{11}$

Desta forma, a assistência de enfermagem em oncologia evoluiu muito desde seu aparecimento com especialidades e a existência de literaturas que apontam e preconizam a importância das intervenções de enfermagem no diagnóstico, prevenção e tratamento adequado do câncer de mama..$^{12}$

0 trabalho se justifica devido o câncer de mama acometer uma grande parcela feminina da nossa sociedade. 0 temor e a grande repercussão da doença devem-se às danosas intervenções sofridas tanto no corpo como na mente da mulher.

A consequência mais grave é a realidade do diagnóstico e a mastectomia, pois abrange $o$ aspecto íntimo, feminino e emocional da mulher, aliados ao desconhecimento da doença, o que soa como uma sentença de morte. 0 câncer de mama pode afetar mulheres de todas as faixas etárias; no entanto, a maior prevalência é a partir dos 50 anos. Nesta fase, a mulher geralmente procura menos o serviço de saúde, por não estar mais no período reprodutivo e se considerar menos vulnerável. No caso das mulheres jovens acometidas pelo câncer, embora menos frequente, é retratada uma realidade mais cruel já que 
estando em plena fase produtiva e reprodutiva a mulher ainda possui filhos dependentes.

Dessa forma, muitas vezes o emocional feminino é pouco considerado, inclusive pelos próprios profissionais de saúde, que ressaltam mais os aspectos físicos e biológicos da mulher, porque são mais visíveis. Entretanto, corpo e mente se comungam, em um processo uno e indivisível. Com base nesta vertente, ocorre uma maior desintegração na vida da mulher e seus familiares, o que provavelmente acarretará mudanças significativas em seu estilo de vida.

Neste sentido, espera-se que o resultado do estudo sirva de nor te, conhecimento e sensibilização por parte dos profissionais de saúde em conjunto com seus gestores, estudantes da área de saúde inserida nesta realidade, para que despertem sobre a importância e relevância de se trabalhar, não só com os aspectos objetivos, mas também com a subjetividade, o que valoriza o ser humano; devem-se aliar a isso atenção, acolhimento e o cuidado fundamentado na ética e respeito pela clientela.

A melhor forma de se evidenciar o problema é reconhecê-lo e oferecer estratégias viáveis para aplicação de possíveis soluções de forma imediata, a fim de interferir positivamente na realidade. Neste contexto, se faz necessário estabelecer metas preventivas e ou detecção precoce da doença, através de educação em saúde continuada, na qual se capacite os profissionais envolvidos na problemática suscitada. Apesar de as medidas preventivas relacionadas ao câncer de mama serem de certa forma conhecidas, ainda não são postas em prática, caso contrário não haveria uma curva ascendente quanto aos índices de câncer, principalmente no grupo feminino.

Diante do exposto, buscou-se conhecer da própria mulher que sofre esse impacto como o seu emocional é afetado e as repercussões ocasionadas na sua vida após o diagnóstico de câncer de mama.

Para tanto, delimitou-se como objeto deste estudo: Os sentimentos das mulheres pós-mastectomia em um ambulatório ginecológico de um hospital de referência de Teresina-PI, e como objetivo: descrever os sentimentos das mulheres sobre o câncer de mama e discutir as mudanças ocorridas na vida da mulher após o câncer de mama.

2 METODOLOGIA

A pesquisa é de natureza qualitativa descritiva, o que permite 0 aprofundamento no mundo dos significados das ações e relações humanas, um lado não perceptível e não captável em equações, médias e estatísticas. ${ }^{13}$

0 campo de estudo escolhido foi o setor ginecológico de um hospital de referência de Teresina-PI, por ser uma área de atendimento a pacientes com câncer de mama, onde as mulheres realizavam o seu tratamento. 0 s sujeitos foram 13 mulheres na faixa etária de 30 a 50 anos. A participação dos sujeitos no estudo teve como critério: 0 diagnóstico do câncer de mama há pelo menos 2 anos, tendo como consequência a realização da mastectomia radical em uma das mamas e possuir discernimento suficiente para aceitar de forma livre e esclarecida a sua participação na pesquisa.

\section{METODOLOGIA}

A pesquisa é de natureza qualitativa descritiva, o que permite 0 aprofundamento no mundo dos significados das ações e relações humanas, um lado não perceptível e não captável em equaç̃oes, médias e estatísticas. ${ }^{13}$

0 campo de estudo escolhido foi o setor ginecológico de um hospital de referência de Teresina-PI, por ser uma área de atendimento a pacientes com câncer de mama, onde as mulheres realizavam o seu tratamento. Os sujeitos foram 13 mulheres na faixa etária de 30 a 50 anos. A participação dos sujeitos no estudo teve como critério: o diagnóstico do câncer de mama há pelo menos 2 anos, tendo como consequência a realização da mastectomia radical em uma das mamas e possuir discernimento suficiente para aceitar de forma livre e esclarecida a sua participação na pesquisa.

A coleta de dados, que foi obtida no primeiro semestre de 2008, deu-se após a autorização do hospital e aprovação do Comitê de Ética em Pesquisa da Faculdade de Saúde Ciências Humanas e Tecnológicas do Piauí-NOVAFAPI. A preservação da identidade dos sujeitos foi garantida por meio da assinatura do Termo de Consentimento Livre e Esclarecido, obedecendo, portanto, aos aspectos éticos e legais descriminados na Resolução nº. 196/96 do Conselho Nacional de Saúde, que estabelece diretriz e normas regulamentadoras de pesquisas envolvendo seres humanos. ${ }^{14} \mathrm{~A}$ presente pesquisa foi aprovada no CEP no dia 25/04/2008, CAAE0047.1.043.000-08.

A técnica de coleta de dados foi aplicada até que houvesse a saturação dos discursos. A entrevista semiestruturada combina perguntas abertas e fechadas e visa ao levantamento de dados pertinentes aos objetivos da pesquisa, devendo permitir a flexibilidade de pensamento dos sujeitos, que têm a possibilidade de discorrer sobre o tema proposto. ${ }^{15}$

Esta entrevista foi desenvolvida por meio de um roteiro de perguntas formuladas pelos autores, considerando os aspectos mais relevantes do problema apresentado. Para 0 registro das entrevistas, utilizou-se aparelho mp3, com duração de 20 a 30 minutos. Os relatos foram imediatamente transcritos na íntegra; logo depois, foram realizadas leitura e releitura dos discursos, a fim de não se perder nenhum conteúdo importante ao bom desenvolvimento da pesquisa. Os dados coletados foram submetidos à análise de conteúdo, modalidade temática, em que se parte de uma leitura de primeiro plano das falas, depoimentos e documentos, para atingir um nível mais profundo, ultrapassando os sentidos manifestos do material. ${ }^{13}$ 
As respostas foram analisadas de acordo com suas similaridades e agrupadas por categorias analíticas utilizadas na construção dos resultados. ${ }^{13}$ Durante a análise os discursos apreendidos foram divididos em três categorias: Sentimentos negativos gerados pela percepção física após mastectomia, sentimentos positivos gerados pelo conforto espiritual e sentimentos gerados pela falta de apoio e atenção dos profissionais durante a assistência.

\section{ANÁLISE E DISCUSSÃO DOS DADOS}

Participaram do estudo 13 mulheres na faixa etária de 30 a 50 anos; a maioria tinha apenas 0 ensino fundamental incompleto (8), era casada (10), com renda familiar em torno de dois salários mínimos (9) e era católica (12). A ocupação predominante foi a de dona de casa (8), sendo que as procedências variam entre os estados do Piauí (9) e Maranhão (4).

As repostas foram analisadas à luz do referencial teórico de autores que referenciaram a mesma temática abordada na pesquisa.

Após a transcrição das entrevistas, os dados foram agrupados em três categorias: Sentimentos negativos gerados pela percepção física após mastectomia; Sentimentos positivos gerados pelo confor to espiritual; Sentimentos gerados pela falta de apoio e atenção dos profissionais durante a assistência.

Sentimentos negativos gerados pela percepção física após a mastectomia

Estas falas refletem uma visão aterrorizada pela mulher em relação à doença, em que a percepção física gera sentimentos negativos, a falta de um pedaço do corpo, gera a sensação de que a pessoa está incompleta, fazendo com que elas incorporem a impotência diante da situação imposta. Eis as falas:

Fico commedo de olharno espelho, devido a terperdido uma parte do corpo, fica estranho, diferente das outras pessoas [...] Não consigo me tocar sem termedo. Olhar e ver a falta dele é muito ruim [...] . (D1)

É esquisito, estranho. Fica faltando uma parte da gente, principalmente quando nós nos vemos no espelho [...]. A gente fica espantada só em ver que está sem ele, é difícil [...]. Eu choro, é ruim mesmo [...]. (D2).

A gente não pensa no peito antes de acontecer isso, e é como se fosse o corpo todo [...]. É mais importante do que a gente pensava. [...] (D3).

É muito diferente essa sensação de está faltando algo. [...] Estou muito triste, não sei o que fazer agora da minha vida. [...] (D12).
0 que se observa em relação às entrevistadas são sentimentos de medo, acanhamento, estranheza, tristeza, espanto, desânimo, ou seja, uma desolação em relação à situação de mutilação a que foram submetidas, sendo que o choque existente em relação à percepção física é mais evidente após a visualização do resultado da mastectomia.

A percepção feminina em relação ao corpo sempre levou o lado estético ao extremo desde pequena, e, quando a mulher se vê na possibilidade de ficar sem uma de suas mamas, a tendência é que venha a se martirizar, porque não sabe como as pessoas irão reagir em relação à sua aparência, principalmente seu parceiro, que poderá chegar a desistir da relação em alguns casos. ${ }^{16}$

Desta forma, o câncer de mama carrega os tabus de uma doença chamada "maldita", possível causadora de desfiguração de partes do corpo e até do próprio atrativo sexual, e traz sofrimentos por seu tratamento ser prolongado. ${ }^{9} \mathrm{E}$ visto também como potencialmente estressor que provoca uma série de transformações na vida, tanto da mulher acometida quanto de seus familiares.

Um ponto importante a ser considerado seria o uso da reconstrução mamária como alternativa para melhoria destes sentimentos negativos. A reconstrução mamária é uma alternativa apresentada normalmente pelo médico, na tentativa de amenizar o estigma e melhorar o aspecto físico quando há possibilidade segura de realizá-la. ${ }^{1}$

Estiveram presentes também em grande parte dos depoimentos expressões de frustração, desânimo, vergonha e desvalorização da auto imagem do próprio corpo, além da não aceitação da condição atual e alterações na sexualidade. Para essas mulheres, a perda da mama ocasionou sentimentos de rejeição e inferioridade, consequentemente fazendo com que haja uma alteração desfavorável da autoestima. Eis os depoimentos:

[...] Não consigo parar nessa tal plástica, a gente nasce direita e morre com defeito, isso eu não consigo entender até agora porque aconteceu comigo, eu não mereço, nunca fiz nada de ruim para merecer tanto sofrimento $[\ldots][\ldots]$ É duro só quem passa por isso, é quem sabe.......] (D4).

[...] Não sou mais a mesma, tenho vergonha do meu marido [...] [...] Acho que nunca vou ter coragem de tirar a minha roupa na frente dele, é muito triste. Até quando ele vai aguentar essa situação é que não sei. É muito feio para a própria pessoa imaginar para outro ver [...] (D5).

[...] Estou me sentindo péssima, estou muito envergonhada. [...] [...] Penso toda hora que tem alguém olhando pra mim [...]. (D1). 
Me senti estranha, muito estranha depois dessa cirurgia; para falar a verdade, não consigo até hoje ficar em frente a um espelho e me olhar sem roupas (D6).

A diminuição da autoestima é um dos maiores problemas encontrados durante o pós-operatório, pois essa sensação de descontrole que provoca impotência diante da mutilação física e o receio de não ser aceita fisicamente podem levar essas mulheres a perder a capacidade em retornar a sua vida normalmente.

A queda da autoestima pode dificultar o tratamento do câncer, sendo uma doença que carrega um estigma com forte repercussão psicológica, que traz uma gama de sentimentos, como: medo, ansiedade, angústia e sobrecarga emocional, desde a descoberta de seu diagnóstico. A doença impõe características de permanência prolongada, e a probabilidade de recidiva com intervenções traumáticas pode alterar o convívio familiar e social. Mediante a isso, a vulnerabilidade a que estão expostos os envolvidos nesta situação de estresse favorece a desestruturação do seu aspecto biopsicossocial. ${ }^{17}$

Após o surgimento do câncer de mama, as mulheres sofrem modificações na sua imagem corporal e autoestima. A doença atinge a unidade corpo-mente e espírito. A assistência prestada a essas clientes deve privilegiar a elevação da qualidade de vida em todos os segmentos de sua vida. Dessa forma, a assistência de enfermagem deve favorecer as mudanças ocorridas no aspecto psicossocial, assim como a readaptação no atual estilo de vida da mulher. ${ }^{19}$

Portanto, para as entrevistadas o resultado da interpretação da experiência da doença e suas consequências físicas desencadeiam sentimentos e emoções a partir do significado de viver com uma doença tão estigmatizante, pois esses significados afetam profundamente a maneira como a mesma percebe sua doença e as respostas de outras pessoas com relação a sua nova condição.

Sentimentos positivos gerados pelo conforto espiritual

Essa categoria reflete a busca de conforto espiritual que auxilia na aproximação das entrevistadas na fé em Deus, sendo este quem as acompanha e consola durante todos os momentos, pois, para elas, é o único capaz de promover o alivio do sofrimento e a cura das enfermidades.

[...] Meu marido e meus filhos estão sempre perto, me dando muita força. Mas eu sei o que eles pensam e sentem, eles têm pena de mim. É assim mesmo, 0 Pai do céu me ergue em todos os momentos que eu precisar ele me da calma e minha família também [...]. (D6.)
[...] Deus éo ponto de apoio, ele que me fortalece e me carrega nessa dificuldade que estou sentindo. Énele que eu posso confiar [...] (D7).

[...] Só Deus para amenizar essa minha dor. Eu não me separo dele nem um minuto, pois é ele que me ajuda e me dá consolo. E peço sempre que me dêforças para suportar isso tudo [...]. (D8).

[...] OPai do Céu me ergue em todos os momentos que eu preciso, ele me dá calma e minha família também [...]. (D9).

[...] Jesus cristo é quem me ilumina, nesse momento tão difícil [...] (D13).

Estes relatos demonstram que o amparo espiritual é responsável por gerar sentimentos positivos para estas mulheres, tais como: força e coragem para superar os obstáculos; confiança, apoio e consolo para amenizar o sofrimento e enfrentar momentos difíceis.

[...] Sempre que penso no meu seio, eu lembro que, se não fosse a fé em Deus, eu poderia estar morta, e não apenas ter perdido o meu seio [...] (D11).

[...] Estou muito triste, mas encontro forças em Deus para superar essas dificuldades [...] (D13).

[...] Tenho muita fé em Deus que tudo vai dar certo e vou superar isso tudo [...] (D10).

[...] Tenho certeza que essa força que eu sinto aqui dentro vem de Jesus, que tanto sofreu para nos salvar [...] (D2.)

Estes depoimentos esboçam uma sensação de confor to e alívio devido a confiança e fé em Deus, pois, para estas mulheres, a fé ajuda a reerguer as suas vidas, a aceitar a sua nova condição, enfrentar as dificuldades e também a sempre tirarem uma visão positiva das coisas.

É necessária a compreensão dessa teia de significados religiosos por todos os envolvidos neste processo de adoecimento, pois essa compreensão pode sinalizar uma promoção em saúde que invista na desconstrução de situações geradoras de sentimentos negativos nestas pacientes, possibilitando a elas mais coragem para lidar com a doença como algo passível de controle, assegurando maior estabilidade emocional. 
A devoção auxilia no enfrentamento de situações de angústia, depressão e medo, que, por sua vez, proporciona apoio e proteção. 0 sofrimento psíquico experimentado pela mulher que vivencia a mutilação, pode variar de acordo com o tempo e a capacidade individual de cada pessoa, que adquire o câncer de mama. A descoberta do diagnóstico favorece a sensação de incerteza do prognóstico, com o pavor da morte. Em paralelo, podem surgir a esperança e a fé, bem como meios que auxiliem no combate a doença. ${ }^{18}$

Portanto, devemos estar cientes do impacto das crenças religiosas sobre a doença, pois muitas vezes a espiritualidade faz parte da saúde de um indivíduo. Assim, as pessoas que sentem Deus em sua vida são capazes de adaptar-se a mudanças inesperadas como o câncer, denunciando a crença dessas mulheres em um ser supremo.

\section{Sentimentos gerados pela falta de apoio e atenção dos profissionais durante assistência.}

Nessa categoria observa-se pelas falas das depoentes a necessidade de mais apoio e atenção por parte das equipes multiprofissionais, pois a falta de apoio e atenção gera nas pacientes expressões de dúvidas, sentimentos de insegurança, desolação, preocupação e tristeza.

[...] O pessoal daqui é bom, mas só diz que tá tudo bem, mas a gente é que sabe. Eu tenho muitas dúvidas [...] [...] Eu não posso fazer nada, só aceitar o que eles dizem, eles estudaram e eu não [...] (D9).

\section{[...] Eles não têm tempo de conversar com a gente.} A gente está nervosa, preocupada, e os que entram aqui falam que está tudo bem. Comentam várias coisas, como já terem feito isso várias vezes e que tem gente que vive com isso a mais tempo, essas coisas, mas ainda estou muito preocupada [...] (D10).

[...] A gente chora e eles vêm, e dizem que é assim mesmo, mas tudo vai ficar bem. Mas a gente sabe como é, é difícil [...] (D5).

[...] Ninguém explica nada direito, só falam que está tudo bem. Não sei como vai ser daqui para frente, se tenho que continuar o tratamento. Não seide nada [...]. (D4).

As entrevistadas demonstraram uma carga emocional muito intensa, pois o câncer é uma doença cheia de estigma que obriga essas mulheres a lidar com sentimentos de enfrentamento da doença.

Os profissionais devem valorizar mais as queixas das pessoas que os procuram. Esta posição favorece a identificação precoce do problema, garantindo melhor prognóstico e qualidade de vida. A participação e colaboração da equipe enfermagem que presta cuidado direto e indireto à cliente é caracterizada por toques, palavras, gestos e sorrisos. 0 cotidiano envolve a interação entre enfermeiros e clientela, necessária para suprir as suas necessidades humanas básicas, como forma de manter a integridade física e psicológica, além de observação de suas respostas aos agressores externos. 0 enfermeiro deve utilizar a linguagem como preciosa ferramenta para se fazer compreender e atingir a interação humana. ${ }^{18}$

É comum que as mulheres se sintam melhores quando os profissionais de saúde fazem perguntas não somente associadas ao seu estado físico, mas também quando demonstram algum interesse pela pessoa e pelas vivências emocionais frequentes ao câncer de mama. ${ }^{16}$

Outro aspecto a ser considerado é a falta de informação ou incentivo por parte dos profissionais na realização do procedimento de reconstrução mamária, pois nenhuma das treze entrevistadas ao falar da cirurgia, dos seus sentimentos e da assistência recebida esboçou algum incentivo ou esclarecimento por parte dos profissionais sobre a realização deste procedimento. Eis os relatos:

[...] Eles estão aqui e me perguntam como estou, olham a minha cirurgia e pronto, não falam nada sobre a doença, se eu posso fazer plástica, nada mesmo [...]. (D3).

[...] A técnica de enfermagem vem e troca o meu curativo. Eu choro muito, todas as vezes, mas ela não diz nada, parece que é tudo normal o meu desespero e a minha angústia [...] (D6).

[...] Não sei o que vai ser daqui para frente, não sei se dá para fazer uma plástica, já perguntei à enfermeira, mas ela disse que só o médico pode responder [...] (D11).

[...] Estou precisando de mais apoio dessas pessoas, porque parece que ninguém se importa com a gente [...] Estou cheia de dúvidas, mas tenho até vergonha de perguntar e não me responderem [...] (D12).

No contexto das atribuições da equipe de saúde, cabe ao enfermeiro realizar um trabalho de incentivo e de suporte emocional para a mulher e sua família do que propriamente um trabalho curativo. Entretanto, percebe-se que pouco tem sido produzido a respeito das estratégias de cuidado adotadas pela enfermagem às mulheres mastectomizadas, sendo que estas estratégias serviriam para o sucesso do tratamento e o bem-estar da clientela. ${ }^{20}$ 
Sendo assim, a assistência às mulheres é fundamental para que elas reconheçam o quadro ao qual vivenciam. Isto é possível com o apoio da equipe multiprofissional que deve oferecer informações em relação ao problema, procedimento cirúrgico, continuidade do tratamento, possibilidades de intervenções estéticas, pois estas informações ajudam a diminuir os sentimentos de dúvida, medo, preocupação e nervosismo gerado pela falta de apoio e ajuda a estas mulheres.

\section{CONSIDERAÇÕES FINAIS}

As mudanças e as dificuldades na vida de uma mulher em função do câncer de mama geram uma gama de sentimentos, o que gera modificações na imagem corporal, autoestima e relacionamento social. A doença atinge a unidade corpo-menteespírito. No entanto, essa experiência pode ser menos traumática e superada gradualmente se houver o apoio dos profissionais de saúde ao considerarem também o aspecto psicossocial da mulher.

E para tanto, a assistência deve ser voltada para melhora da qualidade de vida em toda a sua amplitude. Sendo assim, a mulher nesse período de adaptação com o "novo" precisa de acompanhamento/apoio profissional e familiar dentro do entendimento que vai muito além da doença em si, pois o que verdadeiramente precisa estar em foco são os sentimentos, as angústias, as dúvidas e as dificuldades destas mulheres e não só sob o aspecto da doença.

Dessa forma, o ser humano deve ser considerado em sua totalidade, de forma holística, o que valoriza o outro em sua singularidade, possibilitando, aos profissionais de saúde, uma visão que privilegie as práticas diárias do assistir a cliente de maneira compreensiva e humanizada.

\section{REFERÊNCIA}

1.Souza AMF. Informações, sentimentos e sentidos relacionados à reconstrução mamária [dissertação de mestrado] Rio de Janeiro (RJ): Instituto Fernandes Figueira; 2008.

2.Silva NCB, Franco MAP, Marques SL. Conhecimento de mulheres sobre câncer de mama e de colo do útero. Paidéia 2005 set/dez; 15(32): 409-16.

3.Ministério da Saúde (BR). Normas e recomendações. Controle do Câncer de Mama. Documento de Consenso. Rev Bras Cancerol 2004; 50(2): 77- 90.

4-Instituto Nacional do Câncer-INCA. Câncer de mama. [on-line]; 2005 [citado 11 abr 2004]. Disponível em: http://www.inca.gov.br// estimativa/2005/index.asp?link=conteudo_view.asp\&id $=5$
5.Junqueira PAA, Fonseca AM. Conhecimento sobre o diagnóstico e rastreamento do câncer de mama entre os ginecologistas do estado de Goiás, Brasil. Rev Assoc Med Bras 2003 jul/set; 49(3): 239.

6.Kligerman J. Estimativas sobre a incidência e mortalidade por câncer no Brasil . Rev Bras Cancerol 2002; 48(2): 175-79.

7- Barros ACSD, Barbosa EM, Gebrim LH. Diagnóstico e tratamento do câncer de mama. [on-line]. In: Projeto Diretrizes. Brasília(DF): Associação Médica Brasileira, Conselho Federal de Medicina; 2001; [citado 06 jun 2007] Disponível em: http:// www.projetodiretrizes.org.br/projeto diretrizes/024.pdf

8.Regis MF, Simões MFS. Diagnóstico de câncer de mama, sentimentos, comportamentos e expectativas de mulheres. Rev Eletr Enferm [online] 2005; [citado 28 maio 2007]; 7(1): 81-6. Disponível em: http:/ /www.fen.ufg.br/revista.

9- Ministério da Saúde (BR). Instituto Nacional do Câncer-INCA. [online]. Controle do câncer de mama. Documento de consenso 2004. [citado abr 2004] Disponível em: http://www.inca.gov.br/publicacoes/ Consensointegra.pdf.

10.Ministério da Saúde (BR). Secretaria de Assistência à Saúde. Instituto Nacional de Câncer- INCA. Relatório anual 2001. [citado 06 maio 2003]. Disponível em: http://bvsms.saude.gov.br/bvs/publicacoes/ inca/relatorio_anual2003.pdf.

11. Duarte TP, Andrade AN. Enfrentando a mastectomia: análise dos relatos de mulheres mastectomizadas sobre questões ligadas à sexualidade. Est Psicol 2003; 8(1): 155-63.

12.Camargo TC, Souza IEO. Atenção à mulher mastectomizada: discutindo os aspectos ônticos e a dimensão ontológica da atuação da enfermeira no Hospital do Câncer III. Rev Latino-am Enfermagem 2003; 11(5): 614-21.

13.Minayo MCS. 0 desafio do conhecimento: pesquisa qualitativa em saúde. $9^{a}$ ed. São Paulo (SP): Hucitec; 2006.

14. Ministério da Saúde (BR). Conselho Nacional de Saúde. Resolução CNS $n^{0} 196$, de 10 de outubro de 1996. Diretrizes e normas regulamentadoras da pesquisa envolvendo seres humanos. [on-line]. [citado 15 out 2000] Disponível em: URL: www.ufrgs.br/hcpa/gppger/ res19696.htm

15. Boni V, Quaresma SJ. Aprendendo a entrevistar: como fazer entrevistas em ciências sociais. Rev Eletr Pós-graduados Sociol Polit [on-line] . 2005 [citado 22 out 2008]; 2(1): 68-80. Disponível em: http;// Disponível em: www.emtese.

ufsc.br.

16-Vieira CP, Lopes MHBM, Shimo AKK. Sentimentos e experiências na vida das mulheres com câncer de mama. Rev Esc Enferm USP 2007; 41(2): 311-16.

17.Marcon SS, Salci MA. Itinerário percorrido pelas mulheres na descoberta do câncer. Esc Anna Nery Rev Enferm 2009 jul/set; 13 (3): $558-66$ 
18 Cavalcanti ACD, Coelho MJ. A linguagem como ferramenta do cuidado do enfermeiro em cirurgia cardíaca. Esc Anna Nery Rev Enferm 2007 jun; 11 (2): 220-26.

19- Caetano JA, Soares E. Mulheres mastectomizadas diante do processo de adaptação do self-físico e self-pessoal. Rev Enferm UERJ 2005 maio/ago; 13 (2): 210-16.

20- Pereira SG, Rosenhein DP, Bulhosa MS, et al. Vivências de cuidados da mulher mastectomizada: uma pesquisa bibliográfica. Rev Bras Enferm 2006; 59(6): 791- 95. 